\title{
Reevaluation and taxonomic clarification of Gigantopteridium and Cathaysiopteris of western equatorial Pangea and their biogeographical significance
}

\author{
Rebecca A. Koll, ${ }^{1}$ William A. DiMichele, ${ }^{2}$ and Steven R. Manchester ${ }^{3}$ \\ ${ }^{1}$ Department of Biology, University of Florida, Gainesville, FL 32611, USA, Florida Museum of Natural History, 1659 Museum Road, PO Box \\ 117800, Department of Paleobiology, NMNH, Smithsonian Institution, Washington, DC 20560, USA 〈rebecca.koll@ufl.edu〉 \\ ${ }^{2}$ Department of Paleobiology, NMNH, Smithsonian Institution, Washington, DC 20560, USA 〈dimichel@ si.edu〉 \\ ${ }^{3}$ Department of Biology, University of Florida, Gainesville, FL 32611, USA, Florida Museum of Natural History, 1659 Museum Road, PO Box \\ $117800\langle$ steven@ flmnh.ufl.edu〉
}

\begin{abstract}
A reassessment of the taxonomic relationships of North American gigantopterids is presented in light of an examination of large populations of specimens housed in the US National Museum of Natural History. Variations in venation and subtle aspects of leaf shape facilitate refined understanding of the relationships and diversity of the North American gigantopterid species leading to an improved understanding of the taxonomic and biogeographic relationships of this group, which are found most abundantly in western equatorial Pangea and Cathaysia. Current literature suggests that there are eight North American genera, however, this study has revealed a morphological overlap of several previously defined genera, leading to the conclusion that Gigantopteridium encompasses the species previously treated as Cathaysiopteris yochelsonii as well as a new species, Gigantopteridium utebaturianum. The transfer of $C$. yochelsonii to Gigantopteridium yochelsonii suggests that Cathaysiopteris may represent a genus endemic to Cathaysia, limiting the biogeographical connection between the regions to Zeilleropteris, Gigantopteridium, Euparyphoselis, and Gigantonoclea.
\end{abstract}

\section{Introduction}

Gigantopterids, an enigmatic group of extinct plants known for their distinctive leaf architecture, including peculiar herringbone or polygonal mesh venation patterns, may hold significant biogeographic and paleoenvironmental information tied closely to their global and stratigraphic distribution. Occurrences of this plant group are most commonly recorded in western North America and eastern Asia, with scattered occurrences elsewhere in the former Pangean equatorial regions, including Turkey, Russia, Korea, and Malaysia (Kawasaki, 1934; Wagner, 1962; Kon'no and Asama, 1970; Burago, 1986). As proposed by Glasspool et al. (2004), gigantopterids are likely not monophyletic in nature and should be treated as an informal group when referring to the full suite of species; Glasspool et al. (2004) further limited gigantopterid sensu stricto to Gigantopteris and Gigantonoclea. Gigantopterids as discussed here include the taxa commonly recovered from western equatorial Pangea. Eight North American genera have been recognized; Gigantopteridium Koidzumi, Cathaysiopteris Koidzumi, Zeilleropteris Koidzumi, Gigantonoclea Koidzumi, Evolsonia Mamay, Delnortea Mamay, Euparyphoselis DiMichele, Looy, and Chaney, and Lonesomia Weber, each represented in North America by a single species (Mamay, 1960, 1967, 1986, 1988, 1989; Mamay et al., 1986, 1988; Weber, 1997; Glasspool et al., 2004; DiMichele et al., 2011). Additional species of some genera also have been described from eastern Asia (Halle, 1927; Koidzumi, 1934, 1936; Gu and Zhi, 1974; Li and Yao, 1983; Shen, 1995; Yao and Liu, 2004; DiMichele et al., 2011).

Rarely have the large-scale systematic or stratigraphic patterns of the entire gigantopterid group been examined in detail, nor have the subtleties and range of morphological variation been considered fully in taxonomic investigations. Historically, a biogeographic connection between Cathaysia and western Pangea has been recognized at the generic level for gigantopterids. These areas were on opposite ends of the Pangean supercontinent and separated by the large Panthalassic Ocean. This study questions the presence of Cathaysiopteris in western Pangea as well as the validity of the generic assignment of Gigantopteridium huapingense (Feng) Shen, the only Cathaysian member of that genus (Liu and Yao, 2002; Booi et al., 2009). Current literature and the results of this study restrict the possible linkages of the two regions to Zeilleropteris, Gigantopteridium, Euparyphoselis, and Gigantonoclea. Although species of these genera described from the two regions certainly share morphological similarities at the generic level, at this time, however, no species are known to occur in both paleogeographic areas. This leaves open the possibility that the similarities of gross leaf architecture may be the result of convergence.

The purpose of this study is to reassess North American Paleozoic Gigantopteridium and Cathaysiopteris and revise 
their diagnoses in an effort to better understand their global representation. This study focuses on Gigantopteridium through examination of specimens attributed to Gigantopteridium americanum (White) Koidzumi, Cathaysiopteris yochelsonii Mamay, and a previously unrecognized species similar to Cathaysiopteris whitei (Halle) Koidzumi, and on published descriptions of Gigantopteridium huapingense and Cathaysiopteris whitei. The result is a reevaluation of taxonomic relationships among these species, which leads further to a reevaluation of the biogeographic distribution of gigantopterid genera. After compilation of foliar morphologic features, including second and third order venation structure and margin characters, we suggest that G. americanum, $G$. yochelsonii, and G. utebaturianum n. sp. comprise a Gigantopteridium morphogroup of one genus with three species, which, to the extent presently understood, is unique to the Euramerican portion of the Pangean equatorial regions.

\section{Geologic setting}

All field localities are in North Central Texas, USA (Fig. 1). This area is on the eastern shelf of the Midland basin (Tabor and Montanez, 2004), which was a coastal zone in western equatorial Pangea during the Cisuralian (early Permian). The terrestrial sediments derived from the Ouachita foldbelt and Muenster highlands to the present day north of the study area. Lithology for the study area transitions from coal-bearing strata, including abundant mudstones, sandstones, and limestones, deposited during the Virgilian (Gzhelian), Late Pennsylvanian into primarily mudstone with deposits of fluvial sandstone bodies and marine limestones deposited during the early Permian. Terrestrial depositional environments found throughout the study area vary among field sites and range from sand-/ gravel-rich channel bars to pointbar and floodplain deposits. Most of the plant-bearing beds were deposited in floodplain lakes, representing abandoned segments of channels, in wetlands developed within such settings, or in waning-flow portions of bars in active-channel settings.

The earliest confirmed gigantopterid fossils in the North Central Texas stratigraphic section are Gigantopteridium and occur immediately above the Elm Creek Limestone, at the base of the Petrolia Formation (Hentz and Brown, 1987). Species of Gigantopteridium, the focus of this paper, have not been found, to date, above the Clear Fork Group. This stratigraphic interval encompasses the late Wolfcampian through the early Leonardian, in American regional terminology, of early Permian age. In international stratigraphic terms, this is the late Artinskian through the early part of the Kungurian, based on marine microfossils extracted from limestones that are part of the regional strata (Wardlaw, 2005). According to the International Union of Geological Sciences 2016 Chronostratigraphic Chart, the Artinskian-Kungurian boundary is at $\sim 283.5 \pm 0.6 \mathrm{Ma}$.

\section{Nomenclature}

The species Gigantopteris americanum was initially described from North America by White (1912) on the basis of specimens collected from the Wichita Formation of North Central Texas in
1909 and 1910. This species was later transferred by Koidzumi (1934) to a new genus, Gigantopteridium. Gigantopteridium has been reported from the early Permian of the southwestern United States as well as the Guadalupian (cf. middle Permian) of southern China, each composed of a single species, G. americanum and G. huapingense, respectively (White, 1912; Shen, 1995).

The type species of Cathaysiopteris, $C$. whitei, was chosen by Koidzumi (1934) when he erected the genus. It originally had been described by Halle (1927) from the middle Permian of the Shihhotse Series of central China as a species of Gigantopteris. As with Gigantopteridium, Cathaysiopteris has been recognized in both the southwestern United States and Chinese floras of Permian age, by a single, morphologically distinct, species in each geographic area. The sole North American species, $C$. yochelsonii, was first noted by Read and Mamay (1964) as a distinctive form and later described by Mamay (1986).

The extent to which the North American species of the genera Gigantopteridium and Cathaysiopteris overlap with each other and possibly with other, related genera has been considered in several publications (Mamay, 1986, 1988; DiMichele et al., 2011), but a formal reclassification of this group of morphologically similar species has not been undertaken until now. For this article, we transfer the North American Cathaysiopteris species, C. yochelsonii, into Gigantopteridium and recognize three species of Gigantopteridium: G. americanum, G. yochelsonii, and G. utebaturianum n. sp.

\section{Materials and methods}

Morphologic descriptions are based on total of 188 specimens, both partial $(>50 \%$ of entire specimen; $\sim 76$ specimens) and fragmentary ( $<50 \%$ of entire specimen; $\sim 112$ specimens). Of these specimens, 146 were determined to be Gigantopteridium americanum; 16 were determined to be Gigantopteridium yochelsonii n. comb.; and 26 were assigned to Gigantopteridium utebaturianum $\mathrm{n}$. $\mathrm{sp}$. As material allowed, each specimen was characterized for gross architecture, leaf venation pattern, and vein density using macromorphology via the naked eye and low-power lenses, and micromorphology via light microscopy. All material used for data collection was examined from original specimens through primary observation.

Repositories and institutional abbreviations.-Paleobotanical specimens analyzed as part of this study were collected during the years 1909-2013 by geologists of the US Geological Survey, USA (USGS) and US National Museum of Natural History, Washington, DC, USA (USNM) and are housed at the collections of the Paleobiology Department of the USNM. All type and illustrated specimens are housed in the USNM fossil plant type and illustrated collection. Additional institutional abbreviations used in this paper include Florida Museum of Natural History, Florida, USA (FLMNH) and Swedish Museum of Natural History, Stockholm, Sweden (NRM). Note: collections described here as formerly held by the USGS have been transferred to the USNM. 

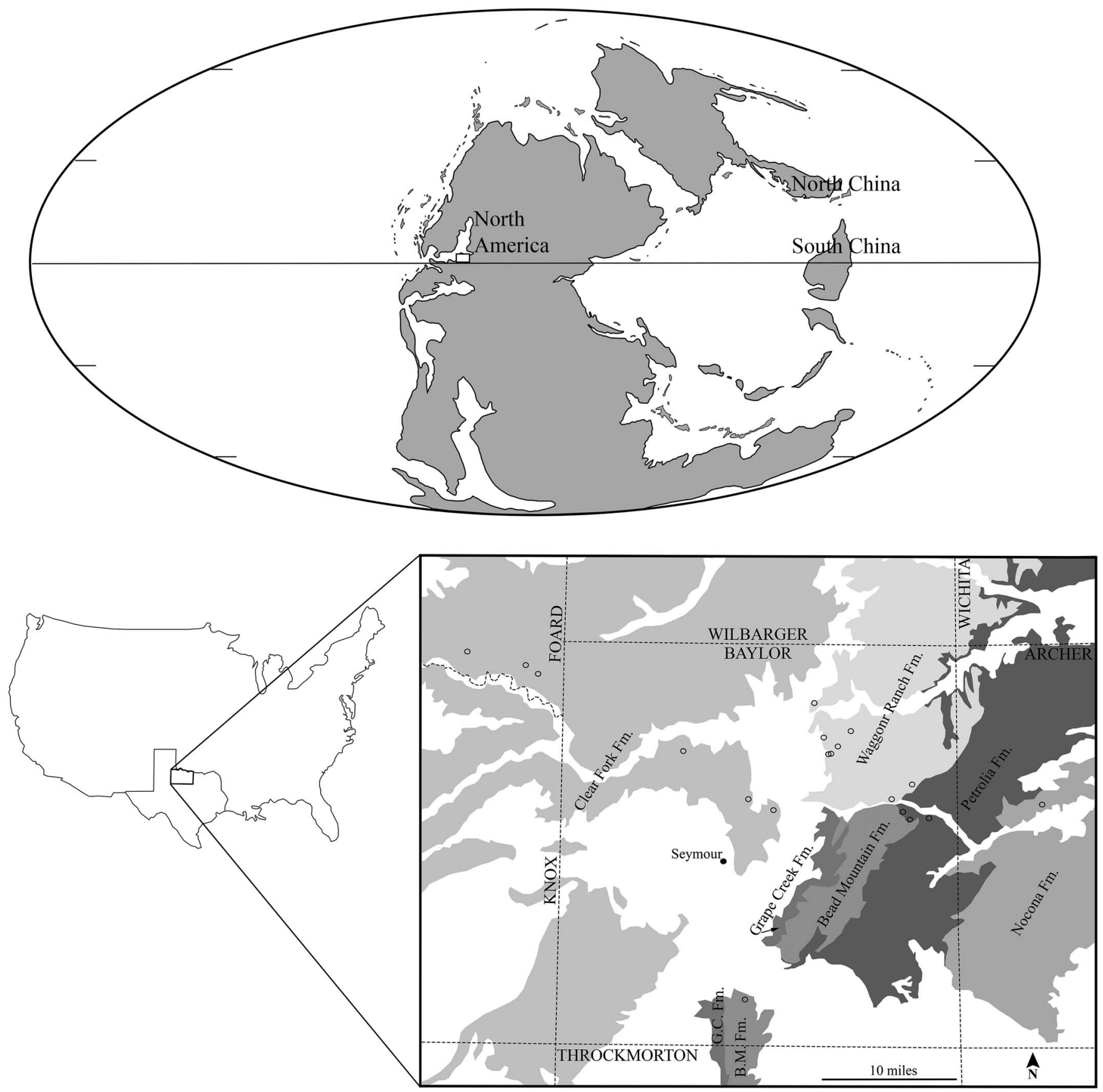

Figure 1. Study area in the paleogeographic and modern geographic context: (Top) paleogeographic map projection of early Permian adapted from @Ron Blakey, Colorado Plateau Geosystems, used with permission, with study region of Texas indicated by white box; (Bottom left) Texas, USA with study region of North Central Texas indicated by black outlined box; (Bottom right) Gigantopteridium collecting localities indicated by open circles, collecting localities; GPS information excluded from figure; Permian geologic formations modified from Hentz and Brown (1987) shown in gray, Pleistocene deposits removed from interpretation.

\section{Systematic paleontology}

Terminology.-Morphology of specimens was characterized using descriptive terminology outlined by Booi et al. (2009). Following these definitions, the venation of the leaf was ordered hierarchically, beginning with the central vein such that the midvein is considered primary or first order venation with successive secondary (second order) venation arising from the primary and tertiary (third order) venation arising from the primary as well as secondary veins. Additionally, subsidiary venation refers to tertiary veins arising directly from the primary vein, whereas accessory veins are defined as tertiary veins, which run nearly parallel to the primary vein, arising from secondary veins.

\section{Genus Gigantopteridium Koidzumi, 1934}

Type species.—Gigantopteridium americanum (White) Koidzumi emend. from North Central Texas. 
Diagnosis.-Leaves oblong to obovate, frequently bifurcated. Margin entire to erose, occasionally sinuous, rarely deeply sinuous. Three orders of venation. Second order venation angle of attachment with primary vein $45-60^{\circ}$, most commonly $60^{\circ}$. Second order veins dissipate before margin, branching dichotomously to reach margin. In specimens exhibiting sinuous to deeply sinuous margins, second order veins may branch to terminate in sinus or apex. Tertiary veins originate from primary vein $80-90^{\circ}$, occasionally slightly obtuse. Tertiary veins originate from secondary veins $40-70^{\circ}$. Tertiary veins may be unbranched or branch up to five times. Branching is most commonly monopodial, though dichotomous branching may also be present. Suture veins may be false, weak, or strong. False suture vein is defined as tertiary veins from adjacent secondary veins approaching one another closely but neglecting to fuse. Suture vein originates at the junction of the subjacent secondary with the primary vein and arches to run perpendicular to primary vein midway between to two adjacent secondary veins terminating at margin.

\section{Gigantopteridium americanum (White) Koidzumi, 1934 emend.}

Figure 2.1-2.7

1912 Gigantopteris americana White, p. 498, pl. 43-49.

1934 Gigantopteridium americanum; Koidzumi, p. 113.

Holotype.-USNM 34070 from the Waggoner Ranch Formation of North Central Texas, USA. Type specimen collected from stream bank approximately one-quarter mile south of the ford of Little Wichita River and four miles southeast of Fulda in Baylor Co., Texas.

Paratypes.-USNM 34061, 34069, 34071, 34072, 34074, 41771, 597058, 597092, 617576, and 636751. We exclude USNM 34062, 34063, 34073, which were cited among the original list of paratypes by White (1912), from our concept of species. Based on our emended diagnoses, USNM 34062 has been reassigned to G. utebaturianum n. sp. USNM 34063 and 34073 do not possess sufficient preservation of high order venation to distinguish species of Gigantopteridium.

Diagnosis.-Leaves oblong to obovate with bifurcation of fronds often present. Margin entire to erose. Three orders of venation. Second order venation angle of attachment with primary vein most frequently $60^{\circ}$. Second order veins branch to terminate at margin. Third order veins arise from primary vein at $80-90^{\circ}$ and most commonly $40-60^{\circ}$ from secondary veins. Third order venation exhibits extensive irregularly spaced monopodial and dichotomous branching into intersecondary space, fusing midway between two adjacent secondary veins to create a strong suture vein. Suture vein originates at junction between subjacent secondary vein and primary vein and terminates at margin.

Description.-Leaves are oblong to obovate in shape with a rounded convex apex (Fig. 2.3). Basal features were not preserved in full for any of the specimens, however, the leaves appear to narrow gradually towards the base. Leaves are likely petiolate. Leaves are commonly bifurcate, with the forking of the primary vein usually occurring approximately one-third of the length from the base at a $45-60^{\circ}$ angle (Fig. 2.7). The margin of the leaf ranges from entire to erose to slightly sinuous (Fig. 2.1-2.3, 2.7). Specimens have three orders of venation (Fig. 2.1, 2.2, 2.4-2.6). The width of the primary vein ranges from $1-6 \mathrm{~mm}$, most commonly $1.5-2.0 \mathrm{~mm}$. Secondary veins are opposite and regularly spaced, inserted decurrently at their point of origin at the primary vein. The angle of attachment of secondary veins with the primary ranges from $45-80^{\circ}$, but is most commonly $60^{\circ}$, becoming slightly more acute distally and more obtuse towards the base. Secondary veins taper just before the margin, in most cases branching dichotomously to reach the margin (Fig. 2.3). In specimens with more pronounced marginal sinuation, secondary veins terminate most commonly in the sinuses, rarely in the apex. Tertiary veins are subsidiary and accessory (Fig. 2.4, 2.5). Tertiary veins arise from the primary vein commonly at $80-90^{\circ}$, occasionally at a slightly obtuse angle. Tertiary veins arising from secondary veins originate at acute angles ranging from $40-80^{\circ}$, most commonly $40-60^{\circ}$, and exhibit extensive, irregularly spaced monopodial and dichotomous branching. Branching of the tertiary veins can originate from the left, right, or both sides of the main vein; tertiaries frequently branch two or three times before reaching the intersecondary suture, although tertiary veins may branch as few as one time or as many as five times (Fig. 2.5, 2.6). Tertiary veins begin to subdivide near the point of origination from the secondary vein and most often branch one to two times with additional branching one-third the distance from the intersecondary suture. Tertiary veins from any pair of adjacent secondary veins fuse to form a strong intersecondary suture vein, which originates at the junction of the subjacent secondary vein and primary vein (Fig. 2.1, 2.2, 2.5). The suture arches slightly to run parallel to the flanking secondary veins, continuing to terminate at the margin. Tertiary veins anastomose with surrounding fascicles from laterally adjacent tertiary veins to form a polygonal mesh and fuse with tertiary veins originating in the opposite secondary to contribute to the intersecondary suture vein.

Remarks.-The findings from the reevaluation of the USNM materials conform to the majority of points outlined in the original diagnosis by White (1912) of Gigantopteris americana, which was transferred to Gigantopteridium americanum by Koidzumi (1934). However, examination of the USNM collection has lead to the refinement of the G. americanum description by designating an additional species (G. utebaturianum n. sp.), segregated from what had been considered a single species of Gigantopteridium. Thus, a formal emendation of the species diagnosis made by White (1912) is required. Here we note that these characters presented in the original diagnosis: (1) secondary vein termination at the margin and in the convexity of sinuate margins, and (2) strong intertertiary sutures, have been redefined because both characters are absent from nearly all G. americanum specimens as we have recircumscribed the species, although they may occur rarely.

Additionally, a review of the current diagnosis of Gigantopteridium huapingense suggests that a new combination removing G. huapingense from Gigantopteridium may be 



Figure 2. Morphology of Gigantopteridium americanum from the Petrolia and Waggoner Ranch formations, early Permian, North Central Texas: (1) incomplete frond showing branching habit of high order venation and suture origination point, USNM 41771; (2) venation diagram of the same specimen; (3) partial frond showing convex apex, erose margin, and secondary vein framework, USNM 617576; (4) incomplete frond showing subsidiary and accessory venation, USNM 597092; (5) close-up of high order venation, USNM 597092; (6) close-up of high order venation, small portion of tertiary branching pattern highlighted in white with arrows indicating branching points, USNM 597058; (7) incomplete frond showing bifurcation of primary vein, USNM 636751. All scale bars $=0.5 \mathrm{~cm} ; \mathrm{b}=$ bifurcation point, $\mathrm{s}=$ suture, $\mathrm{so}=$ suture origination point, $\mathrm{t}=$ termination of secondary vein.

in order, however formal reassignment is outside the scope of this paper. Gigantopteridium huapingense differs from G. americanum, G. yochelsonii, and G. utebaturianum n. sp. by the: (1) occurrence of an asymmetrical lamina; (2) serrate to undulate margins; (3) a more consistently obtuse angle of insertion of tertiary veins at their point of origin from secondary veins, ranging from $60-80^{\circ}$; (4) sympodial branching habit of tertiary veins; (5) structure of the tertiary vein branching, which occurs initially at the point of origination from the secondary vein, resulting in an anadromous vein running parallel to flanking secondary veins before branching six to seven times into the intersecondary space, forming distinct fascicles; and (6) origination of a single tertiary vein from the primary vein midway between two adjacent secondary veins, creating accessory mesh perpendicular to secondary veins. In earlier investigations of G. huapingense, both Liu and Yao (2002) and Mamay (1986) discussed the possibility of the unbifurcated lamina forming a pinnately compound leaf, common to Cathaysian gigantopterids, however, at present there is insufficient evidence to support this idea.

Gigantopteridium yochelsonii (Mamay) new combination Figure 3.1-3.7

1986 Cathaysiopteris yochelsonii Mamay; Read and Mamay, 1964, p. K15, pl. 19, fig. 2. 



3
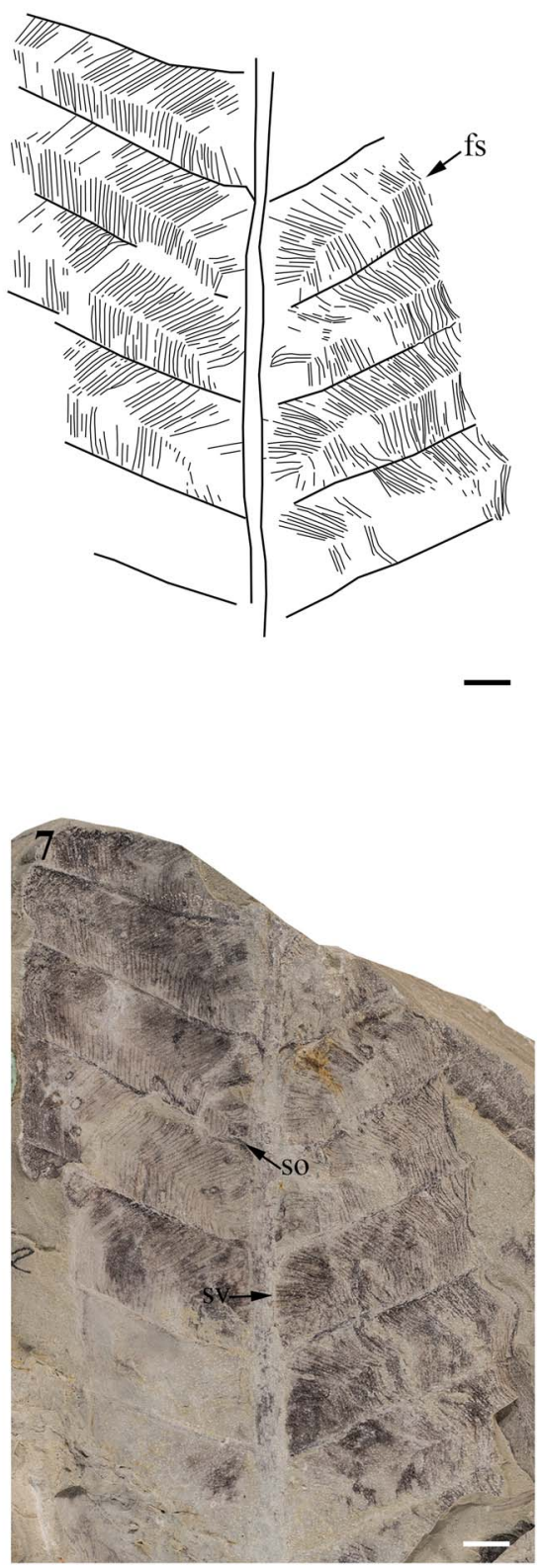

Figure 3. Morphology of Gigantopteridium yochelsonii from the Waggoner Ranch formation and Clear Fork Group, early Permian, North Central Texas: (1) partial frond showing bifurcation of primary vein, slightly erose margin, subsidiary and accessory venation, and false suture origination point, USNM 41776; (2) same specimen, detail of high order venation, showing subsidiary veins and high order branching; (3) venation diagram of specimen with false sutures indicated by arrow, USNM 617578; (4) fragmentary frond showing suture and high order venation, small portion of venation highlighted in white, USNM 406022; (5) close-up of high order venation and secondary vein termination approaching margin, false suture indicated, USNM 406021; (6) nearly complete frond showing assumed bifurcation and primary vein framework of USNM 406021; (7) incomplete frond diagrammed in (3) showing suture origination point and subsidiary veins indicated by arrows, USNM 617578. All scale bars $=0.5 \mathrm{~cm} ; \mathrm{b}=$ bifurcation point, fs $=$ false suture, so $=$ suture origination point, $\mathrm{sv}=$ subsidiary veins.

Holotype.-USNM 41776 from the Clear Fork Group, North Central Texas, USA. Type specimen collected from a quarry approximately six miles SW of Lawn, Texas.

Paratypes.-USNM 406021, 406022, 406024, 406025, and 617578 . The following specimens from the original paratype suite of Mamay (1986) are excluded: 406023, 406026, and 406027. Based on our emended diagnoses, USNM 406023 is assigned to
G. utebaturianum n. sp. USNM 406026 and 406027 do not exhibit sufficient preservation of high order venation necessary for confidently assigning to Gigantopteridium species.

Diagnosis.—Leaves oblong to obovate, becoming more acute toward base. Fronds often bifurcated. Margin erose to entire, rarely sinuous. Three orders of venation. Secondary veins originate from primary vein at $50-60^{\circ}$. Third order veins arise 
from secondary veins at $45-60^{\circ}$. Tertiary veins are evenly spaced along secondary vein from which they originate, rarely branching. False suture vein produced between adjacent secondary veins by tertiary veins that closely approach those from adjacent secondary veins, but do not fuse with them.

Description.-Leaves are oblong to obovate and petiolate (Fig. 3.1, 3.6). Leaf apex is convex and rounded, whereas the base narrows slightly to become slightly acute. Leaves bifurcate once with forking occurring one-half to one-third of the length from the base (Fig. 3.1). The angle of bifurcation commonly is $45^{\circ}$. The margin is most often entire to erose, rarely sinuous (Fig. 3.1, 3.2, 3.5, 3.6). Specimens have three orders of venation (Fig. 3.1-3.3, 3.6, 3.7). Midvein width 1-3 mm. Secondary veins are pinnate and opposite with regular spacing. The angle of attachment of secondary veins to the midvein is acute, ranging from $50-60^{\circ}$, all exhibiting decurrent attachment to the primary vein (Fig. 3.1, 3.6, 3.7). Secondary veins dissipate just before the margin to terminate in dichotomous branches that continue to the margin. Secondary veins termination rarely preserved in the specimens examined, however appears to terminate in the sinus or apex of the more sinuate specimens. Subsidiary and accessory intersecondary tertiary veins are present. Tertiary veins originating from primary vein at $80-90^{\circ}$ (Fig. 3.2, 3.7). Tertiary veins originating from secondary veins are opposite and arise at an acute angle ranging from $45-60^{\circ}$, most commonly $45^{\circ}$. Tertiary veins are evenly spaced along a secondary vein, are straight to slightly arched and very rarely branched, but if branched, the branching is monopodial and occurs once at or near the point of attachment to the secondary vein. Tertiary veins from adjacent secondary veins terminate in the intersecondary space. The tertiary veins from adjacent secondary veins approach one another closely, but do not fuse, thus creating a false suture vein feature arising between any pair of adjacent secondary veins at the point where the subjacent secondary joins the midvein; the false suture vein thus is initiated a short distance from the midrib and then arches slightly to run parallel to the secondary veins, midway between them, in the intersecondary space continuing to the margin (Fig. 3.2-3.4, 3.7).

Remarks.-The concept of Gigantopteridium yochelsonii presented here includes foliar traits that were not part of the original diagnosis of Mamay (1986): (1) increased variability in margin character, formerly described as sinuous or crenate, now including specimens exhibiting entire margins; (2) a smaller range of variability and more acute angle of insertion of secondary veins at their point of origin from the primary, previously $30-80^{\circ}$ but found here to originate at $50-60^{\circ}$, with the angle slightly more acute distally and slightly more obtuse towards the base; (3) branching of the major secondary veins just before the margin, the vein forking to reach the margin; (4) reduced variation in the angle of insertion of the tertiary veins to the secondary veins, formerly described as ranging from $50-75^{\circ}$, but most commonly seen in this study to be $\sim 45^{\circ}$; and (5) lack of a true suture vein previously described as formed through the fusion of tertiary veins from adjacent secondary veins in the intersecondary space, however, this study found that tertiary veins rarely fuse either with those from the adjacent secondary or with those positioned laterally adjacent, originating from the same secondary. Furthermore, there is little fusion between adjacent tertiary veins even at their termination points. Thus, there is no suture vein that continues strongly from the midvein to the margin.

Mamay (1986) noted a resemblance between G. yochelsonii and the Cathaysian species, Cathaysiopteris whitei (Halle) Koidzumi, citing the presence of three orders of venation, intersecondary sutures, and the general simplicity of the higher order venation resulting from a lack of branching of the tertiary venation. Although we agree that the two species have similar foliar traits, comparison of the $C$. whitei literature with the diagnosis of G. yochelsonii described here as well as the establishment of another species, Gigantopteridium utebaturianum n. sp. (described below), clarifies the unique characteristics for each species, and thus provides justification to maintain their distinction (Figs. 3, 4).

Mamay (1986) distinguished G. yochelsonii from C. whitei on the basis of variation of several features: (1) the angle of insertion of secondary veins at their point of attachment to the primary vein, ranging from $30-80^{\circ}$ in G. yochelsonii and $90^{\circ}$ in C. whitei; (2) the angle of insertion of tertiary veins to secondary veins, $50-75^{\circ}$ in $G$. yochelsonii and more acute in C. whitei $\left(\sim 30^{\circ}\right)$; (3) secondary vein termination points, at the margin in G. yochelsonii, but just before the margin branching into dichotomously forking veins to reach the margin in $C$. whitei; and (4) the origination of the suture vein at the junction of the subjacent secondary and primary veins in G. yochelsonii and midway between two adjacent secondary veins directly from the primary vein in $C$. whitei. It can be noted, in addition to Mamay's original observations, that $C$. whitei has a distinct suture vein created by the fusion of tertiary veins originating from adjacent secondary veins, which contrasts strongly with the presence of a false suture in G. yochelsonii (Fig. 3.4).

We found that both $G$. yochelsonii and the new species of Gigantopteridium are morphologically distinct from Cathaysiopteris. In agreement with the conclusion of Mamay (1986), this study finds the key differences distinguishing G. yochelsonii from $C$. whitei to be the origination point and presence or absence of the intersecondary suture, a false suture originating at the junction of the primary and lower secondary veins and arching into the intersecondary space to meet the margin in G. yochelsonii and a robust suture originating directly from the primary vein midway between two adjacent secondary veins running parallel to the margin in $C$. whitei, and the lack of ultimate order branching in $G$. yochelsonii versus a habit of two-three dichotomous branches in $C$. whitei. The comparison of G. utebaturianum n. sp. and C. whitei is discussed below.

Genus Gigantopteridium Koidzumi, 1934
Gigantopteridium utebaturianum new species Figure 4.1-4.8

Holotype.-USNM 597099 (USNM locality number 40042).

Paratypes.-USNM 406023, 597075, 597138, 617577, and 636752.

Diagnosis.—Leaves oblong to obovate. Margin entire to erose, occasionally sinuous. Three orders of venation. Angle of 

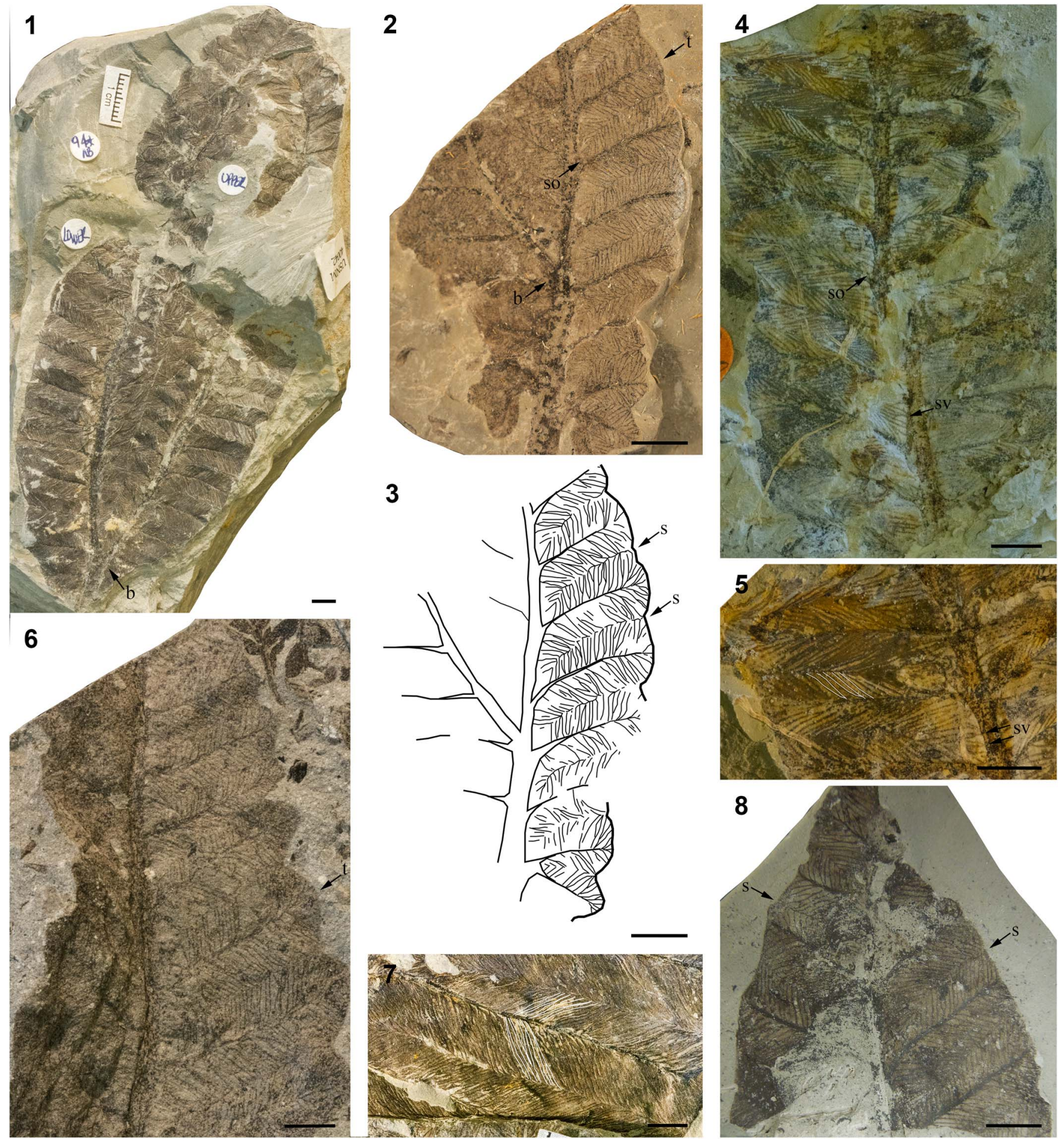

Figure 4. Morphology of Gigantopteridium utebaturianum n. sp. from the Petrolia and Waggoner Ranch formations, early Permian, North Central Texas: (1) holotype USNM 597099, nearly complete frond showing bifurcation of primary vein; (2) paratype USNM 617577, partial frond showing erose margin, subsidiary and accessory venation, and suture origination point; (3) venation diagram of same specimen; (4) paratype USNM 636752, partial frond showing subsidiary and accessory veins and suture origination point; (5) same specimen, detail of high order venation with subsidiary veins indicated and tertiary vein structure highlighted in white; (6) paratype USNM 597138, partial frond showing sinuate margin and second order vein termination; (7) paratype USNM 597075, detail of venation showing weak suture and dichotomously branched tertiary veins; (8) paratype USNM 406023, partial frond believed to be near apex showing both weak sutures. All scale bars $=0.5 \mathrm{~cm} ; \mathrm{b}=$ bifurcation point, $\mathrm{s}=$ suture, $\mathrm{so}=$ suture origination point, $\mathrm{sv}=$ subsidiary veins, $\mathrm{t}=$ termination of secondary vein.

attachment of secondary veins to primary vein is $45-60^{\circ}$. Tertiary veins arise from primary vein at $90^{\circ}$ or slightly obtuse angle. Tertiary veins arise from secondary veins at $50-75^{\circ}$.
Tertiary veins branch once or twice monopodially and fuse with tertiary veins from adjacent secondary vein midway into the intersecondary space. Weak suture vein is common. 
Occurrence.-Type locality is found in Baylor County, TX, on the Fulda 7.5 ' USGS quadrangle map. Exact location of the type locality is on file at the USNM and is withheld here at the request of the property owner. Stratigraphic position of type specimen is Waggoner Ranch Formation.

Description.-Leaf shape is oblong to obovate (Fig. 4.1). Several specimens exhibit bifurcation of the lamina accompanied by forking of the primary vein approximately one-third of the length from the base (Fig. 4.1-4.3). Apex shape of the resultant portions of the leaf is rounded convex, but may trend to slightly acuminate. The base of the leaf, which is known from only a single specimen, is distinctly asymmetrical. Margin character ranges from entire to erose to sinuous, occasionally deeply sinuous (Fig. 4.1-4.3, 4.6). Secondary veins are regularly spaced, pinnate and opposite in their attachment to the primary vein. Secondary attachment to the midvein is slightly decurrent. The angle of attachment ranges from $45-60^{\circ}$, most commonly $60^{\circ}$. Secondary veins terminate just before the margin and, if the specimen has a lobed margin, may terminate in the apex or sinus (Fig. 4.2, 4.3, 4.6). Tertiary veins are both subsidiary and accessory (Fig. 4.2-4.5). When arising from the primary vein, tertiary veins originate at a right or slightly obtuse angle. Tertiary veins arising from major secondary veins are decurrent in attachment, opposite, and borne at an acute angle, ranging from $50-75^{\circ}$. Tertiary veins tend to be evenly spaced and straight. Tertiary veins commonly branch one to two times, rarely unbranched (Fig. 4.2-4.8). Branching of tertiary veins is monopodial and occurs initially near their point of origination from the secondary vein, with a possible second forking just before the intersecondary suture (Fig. 4.5, 4.8). Branches of the tertiary veins can originate from either side of the principal tertiary vein; most commonly the veinlets originate in a series of successive divisions. A weakly developed suture vein is present between adjacent secondary veins, formed by the fusion of tertiary veins from adjacent secondary veins. The suture vein originates at the junction of the subjacent secondary with the primary vein; because the suture vein is generally weakly developed, it may not strongly connect the midvein to the margin and may appear to be lacking in some specimens (Fig. 4.2, 4.3, 4.5, 4.7, 4.8).

Etymology.--Named in honor of Dr. Sergius Mamay, who worked extensively on the paleobotany of equatorial Pangea during his career with U.S. Geological Survey. Dr. Mamay credited himself as being the only left-handed, Jewish, piano playing, paleobotanist of Ukrainian descent. Greek, utebaturia ("left-handed").

Remarks.-In his 1986 publication, Mamay stated the materials he analyzed may include two morphologically distinct leaf forms within G. yochelsonii, however the fragmentary nature of the material prevented investigation or confirmation of this possibility. Examination of the full suite of materials now available indicates that there is sufficient evidence to support the establishment of the additional species named here, G. utebaturianum n. sp. Recognition of G. utebaturianum n. sp. specimens as a distinct species, and thus separating them from
G. americanum and G. yochelsonii, allows for the latter two species to be more clearly circumscribed.

Although it shares several traits of gross leaf architecture with both $G$. americanum and G. yochelsonii, G. utebaturianum n. sp. can be distinguished from them on the basis of several traits, including the angle of insertion of the tertiary veins at their point of origin from the secondary veins, the extent of tertiary branching, and structure of the intersecondary suture (compare Figs. 2, 3 with Fig. 4). Gigantopteridium utebaturianum n. sp. is characterized by: (1) a more obtuse angle of insertion of those tertiary veins that arise from the secondary veins, $50-75^{\circ}$ in G. utebaturianum n. sp., $30^{\circ}$ in $G$. americanum, and $45^{\circ}$ in $G$. yochelsonii; (2) moderate branching of one to two times in tertiary veins, as compared with two to five times in G. americanum and zero to one time in G. yochelsonii; and (3) a weak intersecondary suture, differing from the welldeveloped suture in G. americanum, which clearly connects to the primary vein and continues to the margin, and the lack of a suture vein in $G$. yochelsonii, creating a narrow open space between the tertiary veins from adjacent secondaries (i.e., what we have described as a "false" suture).

Of the three North American Gigantopteridium species recognized here, G. utebaturianum n. sp. appears to share the greatest morphological similarity with the Chinese species, Cathaysiopteris whitei. In particular, these two species have limited branching of tertiary veins, creating a distinct "herringbone" appearance. This is a striking feature and gives them an appearance of great similarity upon initial examination. However, it does not appear that G. utebaturianum n. sp. and C. whitei represent the same species based on two important differences, as discussed below.

Structure of tertiary veins.-In G. utebaturianum n. sp. the tertiaries originate from the secondary veins at an angle of $50-75^{\circ}$ then branch just beyond their point of origination from secondary vein, followed occasionally by a second branching just before termination. In contrast, the tertiary veins of $C$. whitei arise from the secondary veins at more acute angles of $15-30^{\circ}$ and extend a few millimeters parallel to the secondary vein before arching into the intersecondary space. They branch initially one-quarter to one-third of the distance between their points of origination and termination, followed rarely by a dichotomous branch just before the intersecondary suture.

The presence of a consistently strong suture in $\mathrm{C}$. whitei.-A consistently strong suture originates directly from the primary vein midway between pairs of secondary veins and extends from the midvein to the margin at a $90^{\circ}$ angle.

Remarks on C. whitei and G. huapingense.-The support for excluding $C$. whitei from Gigantopteridium requires further evaluation as initial morphological evidence indicates it may represent a fourth species within the Gigantopteridiummorphogroup. Defining characters encompassing the three North American Gigantopteridium species clearly distinguish the genus from other gigantopterid genera, however within the genus, traits fall within a range of more-or-less continuous variability. Currently, $C$. whitei is distinguished from North American Gigantopteridium based on: (1) a more obtuse angle 
of origination of secondary veins from the primary vein, with the angle of insertion ranging from $80-90^{\circ}$ in $C$. whitei and averaging $\sim 60^{\circ}$ in all Gigantopteridium species; (2) a more acute angle of origination of tertiary veins from secondary veins, ranging from $15-30^{\circ}$ in C. whitei and $45-80^{\circ}$ in Gigantopteridium species; (3) inconsistencies in the tertiary branching structure, where $C$. whitei branches exclusively dichotomously whereas Gigantopteridium species branch dichotomously and monopodially; (4) accessory mesh running parallel to the midvein formed by the ultimate order of venation in $C$. whitei and absent in North American Gigantopteridium species; and (5) the origination of a pronounced, straight intersecondary suture in $C$. whitei midway between two adjacent secondary veins differing from the origination of an often zig-zagging suture zone at the junction of a secondary vein with the primary vein in Gigantopteridium (Table 1).

As previously stated, G. huapingense likely should be segregated within a distinct genus from Gigantopteridium as it is defined in this paper. Liu and Yao (2002) described G. huapingense as exhibiting accessory mesh, which is a unique trait lacking from North American Gigantopteridium, but (questionably) present in C. whitei, as described by Yang (1987) and Liu and Yao (1992). Preliminary analysis of C. whitei specimens from the collections of Halle (1927) via images provided by the NRM suggests that accessory mesh may be absent from $C$. whitei. If indeed absent, this would be an additional feature supporting the removal of $G$. huapingense from Gigantopteridium.

Remarks on species occurrence.-The pattern of occurrence for each Gigantopteridium species throughout North Central Texas seems to support the designation of three distinct species. Of the identifiable specimens, G. americanum was the most commonly recovered species, while both $G$. yochelsonii and G. utebaturianum n. sp. were found to be rare. Gigantopteridium americanum appeared as the sole species present at localities as well as co-occurring with $G$. utebaturianum n. sp. Gigantopteridium yochelsonii occurred at localities only as the sole Gigantopteridium species present and occasionally in assemblages with Zeilleropteris wattii. Localities with only G. americanum present ranged in numbers of specimens from one to more than thirty identifiable leaves. Two localities presented co-occurrence of G. americanum and G. utebaturianum n. sp. composed of $\sim 170$ and $\sim 54$ Gigantopteridium specimens, respectively, with $G$. americanum the most common and G. utebaturianum n. sp. being rare. One locality presented G. utebaturianum n. sp. as the sole species present, represented by a single identifiable specimen and four additional specimens identifiable to Gigantopteridium.

\section{Conclusion}

Members of North American Gigantopteridium are fairly uniform in gross leaf architecture; sharing features of broad, ribbon-like leaves that appear to be consistently petiolate, have convex apices, leaf bifurcation, and similar primary and secondary vein fabric. The ultimate order venation is crucial for distinguishing the three North American species; however, the distinctive herringbone arrangement of the higher order

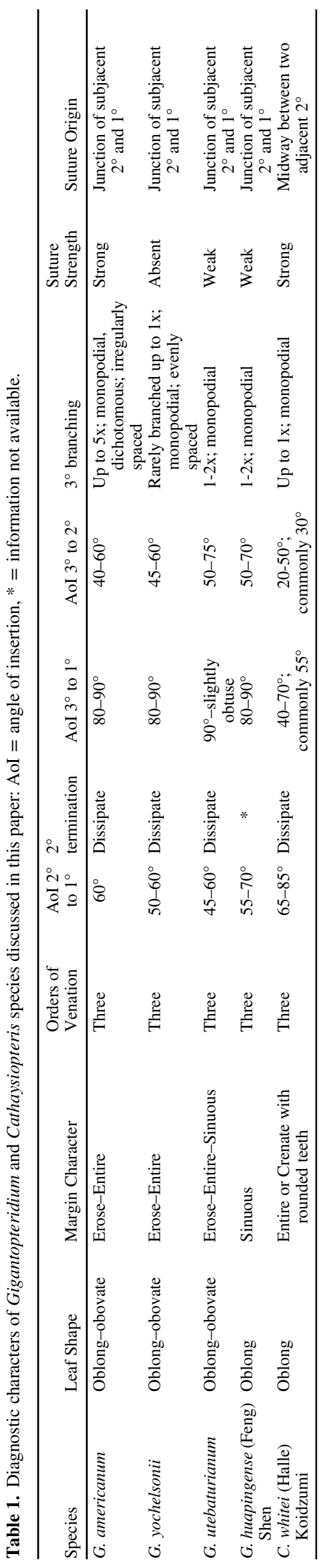




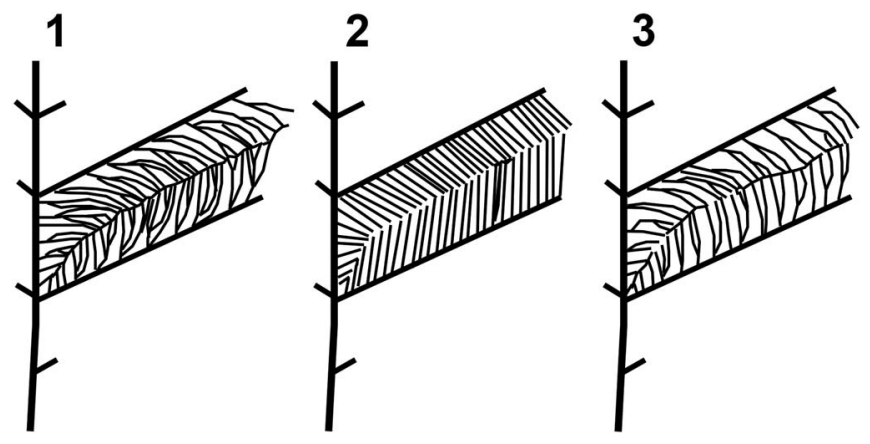

Figure 5. Gigantopteridium high order venation diagrams: (1) Gigantopteridium americanum, showing multiple branched tertiary veins and prominent intersecondary suture vein; (2) Gigantopteridium yochelsonii, showing typically unbranched tertiary veins and false suture; (3) Gigantopteridium utebaturianum n. sp., showing dichotomously branched tertiary veins and weak intersecondary suture vein.

venation in G. yochelsonii may have contributed to its earlier classification as a different genus, but overlapping in some traits with species of Gigantopteridium. This combination of lumping and splitting went so far as to lead to the suggestion of intergeneric hybrids, when, in fact, it appears that there was a set of three distinct, morphologically "adjacent" species. The primary distinguishing characters of each of the three species are subtle, most importantly in the: (1) angle of insertion of secondary and tertiary venation; (2) degree of tertiary branching; and (3) strength, or lack thereof, of a suture vein (Fig. 5 and Table 1). The more robust and obvious characters of leaf shape and the herringbone pattern have, understandably, caused the finer features to be rather overlooked until such time as it was possible to amass many specimens from each species and examine them side by side. It is important to note that the variability in the highest order of venation was acknowledged in the original diagnosis of Cathaysiopteris yochelsonii by Mamay (1986), who stated that there appeared to be some overlap of characters between the North American Gigantopteridium and Cathaysiopteris species possibly indicating the presence of an intermediate form. The evidence compiled in this study does not support the interpretation of Gigantopteridium utebaturianum n. sp. as an intermediate form between two genera, but suggests, rather, a separate, although related entity within a single genus.

Fossil evidence supports a generic-level biogeographical connection between Cathaysia and equatorial Pangea for Zeilleropteris, Gigantopteridium, Gigantonoclea, and Euparyphoselis. The case for Gigantopteridium, as discussed above, remains in some doubt. Similarly, although Gigantonoclea has been described from both regions, the known U.S. specimens are tiny scraps showing only ultimate venation. No attributes of leaf architecture are known for American specimens, and thus the possibility remains that these may not actually be congeneric with Chinese material. The transfer of G. yochelsonii from Cathaysiopteris to Gigantopteridium following the results of this study of North American Gigantopteridium taxonomy indicates endemism of Cathaysiopteris in Cathaysia and disjunction in global distributions of these genera. The comparison of previously diagnosed Pangean and Cathaysian species leads us to question the previously inferred connection between the two regions for both Cathaysiopteris and Gigantopteridium, however more thorough evaluation of Cathaysian $G$. huapingense and $C$. whitei is necessary to fully understand the global distribution and biogeographical relationships of these genera.

\section{Acknowledgments}

We are grateful to D. Chaney (Smithsonian Institute) for his support, patience, and expertise conducting fieldwork, managing collection specimens, and for sharing his knowledge of the study region. We also wish to thank S. Simon (Dalhousie University) for her assistance during field collection and for her insight into the sedimentology of the study region. We are deeply indebted to the property owners involved with this study for allowing permission to access exposures. We also wish to acknowledge the scientists and private individuals who have contributed to amassing of the USNM collection, without whom this study would not have been possible, including but not limited to: C.B. Read, S. Mamay, A. Watt, N. Hotton III, E.C. Olson, R. Hook, D. Gregg, K. Craddock, and J. Nelson. We thank Dr. S. Mcloughlin (NRM) for providing images of Cathaysiopteris whitei from Halle (1927) specimens, which permitted a clearer understanding of currently diagnosed morphologic features. We thank H. Wang (FLMNH) for his help with accessing the Chinese literature. This work was supported by the American Philosophical Society through the Lewis and Clark Fund for Exploration and Field Research.

\section{References}

Booi, M., Van Waveren, I.V., and Van Konijnenburg-Van Citert, J.H.A., 2009, The Jambi gigantopterids and their place in gigantopterid classification: Botanical Journal of the Linnean Society, v. 161, p. 302-328.

Burago, V., 1986, The problem of the Angarian and Cathaysian Kingdom boundary, in Zakharov, W.D., and Onoprienko, Y.I., ed., Permian-Triassic events during the evolution of north-east Asia biota: Vladivostok, Russia, Far Eastern Scientific Centre, USSR Academy of Science, $128 \mathrm{p}$.

DiMichele, W.A., Looy, C.V., and Chaney, D.S., 2011, A new species of gigantopterid from the Middle Permian of the United States and China and its relevance to the gigantopterid concept: International Journal of Plant Sciences, v. 172, p. 107-119.

Glasspool, I.J., Hilton, J., Collinson, M.E., Wang, S. J., and Cheng-Sen, L., 2004, Foliar physiognomy in Cathaysian gigantopterids and the potential to track Palaeozoic climates using an extinct plant group: Palaeogeography, Palaeoclimatology, Palaeoecology, v. 205, p. 69-110.

$\mathrm{Gu}$, and Zhi, eds. (= Institute of Geology and Palaeontology and the Institute of Botany, Academia Sinica), 1974, Palaeozoic plants from China: Fossil Plants of China, 1: Beijing, Science Press, p. 1-226. [in Chinese]

Halle, T.G., 1927, Paleozoic plants from Central Shansi: Palaeontologica Sinica, v. 2, p. 1-316.

Hentz, T.F., and Brown, L.F., Jr., 1987, Wichita Falls-Lawton Sheet in Bureau of Economic Geology Geologic Atlas of Texas The University of Texas at Austin, scale 1:250,000.

Kawasaki, S., 1934, The flora of the Heian System: Bulletin of the Geological Survey of Chosen (Korea), v. 6, p. 47-311.

Koidzumi, G., 1934, Notes on Gigantopteris flora: Acta Phytotaxonomica et Geobotanica, v. 3, p. 112-114.

Koidzumi, G., 1936, The Gigantopteris flora: Acta Phytotaxonomica et Geobotanica, v. 5, p. 130-139.

Kon'no, E., and Asama, K., 1970, On the Gigantopteris flora: Acta Phytotaxonomica et Geobotanica, v. 5, p. 130-144.

Li, X., and Yao, Z-Q., 1983, Current studies of gigantopterids: Palaeontologia Cathayana, v. 1, p. 309-326.

Liu, L-J., and Yao, Z-Q., 1992, On venation of Emplectopteridium alatum Kawasaki: Acta Palaeontologica Sinica, v. 31, p. 646-656.

Liu, L-J., and Yao, Z-Q., 2002, Comparison in leaf architecture between Chinese and American species of Gigantopteridium: Acta Palaeontologica Sinica, v. 41 , p. $322-333$.

Mamay, S.H., 1960, Gigantopteridaceae in Permian floras of the southwestern United States: US Geological Survey Professional Paper, v. 400-B, p. B380. 
Mamay, S.H., 1967, Lower Permian plants from the Arroyo Formation in Baylor County, north-central Texas: United States Geological Survey Professional Paper 575-C, p. C120-C126.

Mamay, S.H., 1986, New species of Gigantopteridaceae from the Lower Permian of Texas: Phytologia, v. 61, p. 311-315.

Mamay, S.H., 1988, Gigantonoclea from the Lower Permian of Texas: Phytologia, v. 64, p. 330-332.

Mamay, S.H., 1989, Evolsonia, a new genus of Gigantopteridaceae from the Lower Permian Vale Formation, north-central Texas: American Journal of Botany, v. 76, p. 1299-1311.

Mamay, S.H., Miller, J.M., Rohr, D.M., and Stein, W.E., Jr., 1986, Delnortea a new genus of Permian plants from West Texas: Phytologia, v. 60, p. 345-346

Mamay, S.H., Miller, J.M., Rohr, D.M., and Stein, W.E., Jr., 1988, Foliar morphology and anatomy of the gigantopterid plant Delnortea abbottiae, from the Lower Permian of West Texas: American Journal of Botany, v. 75, p. 1409-1433.

Read, C.B., and Mamay, S.H., 1964, Upper Paleozoic floral zones and floral provinces of the United States: U.S. Geological Survey Professional Paper 454-K, p. K1-K35.

Shen, G., 1995, Permian Floras, in Li, X., ed., Fossil Floras of China Through The Geological Ages: Guangzhou, China, Guangdong Science and Technology Press, p. 127-223.

Tabor, N.J., and Montanez, I.P., 2004, Morphology and distribution of fossil soils in the Permo-Pennsylvanian Wichita and Bowie Groups, north-central
Texas, USA: implications for western equatorial Pangean palaeoclimate during icehouse-greenhouse transition: Sedimentology, v. 51, p. 851-884.

Wagner, R.H., 1962, On a mixed Cathaysia and Gondwana flora from SE Anatolia (Turkey): Compte rendu, 4e Congres International de Stratigraphie et de Géologie du Carbonifére, v. 3, p. 745-752.

Wardlaw, B.R., 2005, Age assignment of the Pennsylvanian-Early Permian succession of North Central Texas: Permophiles, v. 46, p. 21-22.

Weber, R., 1997, How old is the Triassic flora of Sonora and Tamaulipas and news on Leonardian floras in Puebla and Hidalgo, Mexico: Revista Mexicana de Ciencias Geologicas, v. 14, p. 225-243.

White, D., 1912, The characters of the fossil plant Gigantopteris Schenk and its occurrence in North America: Proceedings of the U.S. National Museum, v. 41, p. 493-516.

Yang, G-X., 1987, The evolution of the Permian gigantopterids in Yuxian County, Western Henan and its geological significance: Geoscience, v. 1, p. $173-195$.

Yao, Z-Q., and Liu, L-J., 2004, A new gigantopterid plant with cuticles from the Permian of South China: Review of Palaeobotany and Palynology, v. 131, p. $29-48$

Accepted 3 April 2017 